\title{
Speech recoding in silent reading
}

\author{
MARYANNE MARTIN \\ University of OXford, OXford, England $O X I 3 U D$
}

\begin{abstract}
Theoretical controversy surrounds the issue of whether or not silent reading involves speech recoding. This was investigated in two experiments by assessing performance on a Stroop color-word task carried out with subjects either silent or articulating irrelevantly (saying "bla" continuously). It was found that the usual decrement in performance resulting from lack of congruency between ink color and color word was attenuated in the articulation condition. The results provide evidence for the presence of speech recoding in silent reading. As a second test of this hypothesis, the Stroop task was also carried out in conjunction with either a graphemic or a phonemic task. The usual decrement in performance was attenuated more by the phonemic than by the graphemic task, therefore providing further support for the hypothesis. The relationship between individual differences in Stroop performance and those in reading speed and in personality (as assessed by the Eysenck Personality Questionnaire) were also examined.
\end{abstract}

Considerable controversy surrounds the issue of whether silent reading usually entails the conversion of the initial visual representation of a printed word into a speech-like form prior to accessing of stored information about the meaning of the word. This recoding hypothesis appears formally as early as in the work of Egger in 1881. He wrote, "to read, in effect, is to translate the writing into speech" (see Edfelt, 1960, p. 14). Two chapters of Huey's classic book (1908) are devoted to "inner speech of reading." More recently, the issue has been investigated as relevant to the question of whether teaching of reading should proceed via the phonic or, alternatively, the whole-word approach (Smith, 1971). The phonic approach is a teaching technique in which individual letter-sound correspondences are learned. The whole-word approach, on the other hand, is based on the premise that readers do not usually identify letters as such, but instead recognize the word as a visual whole.

Two contrasting hypotheses may be formulated about the recognition of printed words. First, a graphemic-encoding hypothesis states that a printed word is recognized directly from a visual representation used to locate stored information about the meaning of the word (e.g., Bower, 1970; Kleiman, 1975; Kolers, 1970). Second, a speech-encoding hypothesis states that recognition involves converting a visual representation into a speech code and that it is the latter which provides access to lexical memory (e.g., Rubenstein, Lewis, \& Rubenstein, 1971). "Speech encoding" is used in this paper as a general term for the

The author wishes to thank Donald Broadbent for reading the manuscript and Czesia James for testing the subjects, and the Science Research Council for their support. Requests for reprints should be sent to Maryanne Martin, University of Oxford, Department of Experimental Psychology, South Parks Road, Oxford, England OX1 3UD. transformation of printed words into any type of speech-based code, for example articulatory or phonemic (see Kleiman, 1975). Integration of the above two hypotheses produces a third possibility. The dual-encoding hypothesis states that lexical memory can be accessed through both visual and phonological representations of a printed word in parallel (e.g., Baron, 1973; LaBerge, 1972). The evidence for each of these hypotheses has been reviewed a number of times (Bradshaw, 1975; Kleiman, 1975; Meyer, Schvaneveldt, \& Ruddy, 1974), but has not so far proved conclusive.

It has, however, been more clearly established that items are held in short-term memory in a speech-like representation irrespective of whether they are presented auditorily or visually (Conrad, 1964; Kleiman, 1975). One experimental method that has been used successfully in this area is the vocal suppression technique. As an example, if people are required to repeat aloud an irrelevant syllable during the presentation of a list, recall is substantially reduced for visually presented lists, but there is little effect on the recall of auditorily presented lists (Levy, 1971; Murray, 1968; Peterson \& Johnson, 1971). Similarly, memory for visually presented sentences is impaired by vocal suppression (Levy, 1975). Thus for memory, the beneficial speech recoding of visually presented material appears to be inhibited by concurrent vocalization.

The possibility to be investigated here is that it is also possible to manipulate phonemic encoding in this way so as to assess its importance in the reading process. Many previous studies in this area have varied the phonemic or graphemic similarity of the materials read, but in these cases the subject may have been alerted (either consciously or unconciously) to these variables, and read the words in an unusual way. To avoid such strategies, a version of the Stroop test was 
used here. Stroop (1935) presented subjects with lists of color words that were printed in different colors. Subjects were required to name the colors while ignoring the words themselves. Performance was found to be inferior to that in a control condition in which the subject named color patches. More recently, the Stroop task has been used as a technique for investigating a wide range of cognitive phenomena, such as hemispheric differences (Cohen \& Martin, 1975; Schmit \& Davis, 1974). Stroop interference effects occur also in tasks that do not require a verbal response, for example, card sorting (Flowers \& Dutch, 1976; Flowers \& Stoup, 1977; Morton \& Chambers, 1973) or manual keypressing (Keele, 1972). For the present purpose of investigating normal silent reading, a nonverbal response is also preferable. In the first experiment, subjects were required to sort cards into piles as fast as possible according to the color of the ink in which a set of letters on each card was written, ignoring the meaning of the color name that the letters comprised. The second experiment was similar but involved the measurement of reaction times to the tachistoscopic presentation of individual cards.

Irrespective of the above theories of reading, it is well established that cards with incongruent words (i.e., differing colors and names) on them should be sorted or responded to according to color slower than cards showing simply a row of colored letters (Xs), due to the interfering effect of the color-word names. An explanation of this effect has been offered by Cohen and Martin (1975) and Morton and Chambers (1973) in terms of a race between information of different types resulting in response competition. It is suggested that interference is greater when the irrelevant attribute of the stimulus (i.e., the written color name) is analyzed faster than the relevant attribute, and the unwanted response is therefore available first. If reading usually entails the phonemic translation of the visual representation in order to access the meaning of a word, this process should be disrupted by the repetition of an irrelevant syllable aloud. In the case of the Stroop test, this disruption of the phonemic code should be beneficial because the meaning of the interfering color word should be suppressed. If the meaning of a word is usually accessed via a graphemic representation, however, or if graphemic information can substitute completely in the absence of phonemic information, the vocal suppression technique should have either no effect or a deleterious one.

In summary, the primary aim of the present experiments was to investigate whether speech recoding occurs in reading by determining whether performance on a Stroop task is improved by vocal suppression. The experiments also allowed an opportunity for the investigation of individual differences in a cognitive task, and these are discussed in detail with respect to Experiment 2.

\section{EXPERIMENT 1}

\section{Method}

Subjects. Ten subjects from the Oxford Long-Term Subject Panel participated in this experiment. There were equal numbers of males and females and their ages were between 18 and 30 years.

Materials. The stimuli were sets of capital letters each $.8 \mathrm{~cm}$ tall and $.5 \mathrm{~cm}$ wide, written in six different colored inks (black, blue, green, purple, red, and yellow) at the centers of $7.6 \times 12.7 \mathrm{~cm}$ blank white cards. The following three different types of packs of cards were prepared, each pack containing 36 cards. Each control card had XXXXX written on it in a particular color. Each congruent card had the name of a color written on it in the same color ink. Each incongruent card had the name of a color written on it in one of the different inks. Eight packs of each of the three types of cards were prepared.

Procedure. The order of occurrence of each of the cards in a pack was randomized using a separate set of random numbers for each subject. In all conditions, subjects were instructed to sort each pack, as fast as possible without making errors, into a set of piles, one ink color to a pile. In addition to the three different types of card, there was a further condition. Subjects were told either to sort the cards in silence or to say "bla" continuously while sorting. The order of execution of these six different experimental conditions was counterbalanced across subjects.

Each subject was tested individually. Typed instructions explained the different types of card sorting. Before each sorting, the subject was informed which of the six conditions applied. He was then handed the pack of cards face upward and told to start. The stopwatch was started simultaneously with the instruction to start and stopped when the last card was placed on its pile. The time taken for each card sort and the number of errors were noted. The first 12 card sorts were treated as practice trials, leaving the second 12 to be used in the analysis reported here.

\section{Results and Discussion}

Mean sorting times averaged over the 10 subjects are shown in Table 1. A three-way analysis of variance (card type by articulation instruction by subjects) was carried out. The main effect of card type was significant $[F(2,18)=12.53, p<.001]$. The interaction between card type and articulation instruction was also significant $[F(2,18)=7.70, p<.01]$. However, the main effect of articulation instruction was not significant $[F(1,9)=.49]$. The mean sorting times were examined further using the Newman-Keuls technique.

The congruent cards were sorted faster than the Xs cards $(\mathrm{p}<.01)$. This is consistent with the hypothesis that word-name information becomes available before that of ink color. The congruent words were sorted significantly slower when subjects were saying "bla"

Table 1

Mean Sorting Times (in Seconds) in Experiment 1

\begin{tabular}{lcccc}
\hline $\begin{array}{c}\text { Type of } \\
\text { Instruction }\end{array}$ & XXXXX & $\begin{array}{c}\text { Con- } \\
\text { gruent } \\
\text { Words }\end{array}$ & $\begin{array}{c}\text { Incon- } \\
\text { gruent } \\
\text { Words }\end{array}$ & $\begin{array}{r}\text { Size of } \\
\text { Stroop } \\
\text { Effect }\end{array}$ \\
\hline $\begin{array}{l}\text { Silent } \\
\begin{array}{l}\text { Continuous } \\
\text { Articulation }\end{array}\end{array}$ & 37.73 & 33.69 & 40.27 & 2.54 \\
\hline
\end{tabular}


than when they were silent $(p<.05)$. This result is consistent with the hypothesis that saying "bla" blocks the phonemic coding route to word naming, as was the finding that it has no significant effect on the sorting of colored Xs. A residual advantage of congruent cards over colored Xs when subjects were saying "bla" $(\mathrm{p}<.05)$ suggests that an alternative direct visual-code route to word naming is also available.

The incongruent cards were sorted significantly slower than the Xs cards $(p<.01)$, confirming the occurrence of the visual Stroop effect in a task in which no verbal response had to be made. The slowing may ive attributed to the difficulty of rejecting misleading word-name information. The most important result was that incongruent cards were sorted faster if the subject was saying "bla" $(p<.01)$, implying that a fast phonemic name route to meaning was blocked or slowed down by irrelevant articulation, reducing confusion with the ink-color naming.

Table 2 shows the mean numbers of sorts per subject in which an error was made. The pattern of errors is similar to that of the sorting times, confirming the above interpretation.

The results of the present experiment provide support for the dual-encoding hypothesis. Figure 1 shows a possible model of reading to take account of the evidence described here. The solid and dotted lines represent, respectively, the definite and the possible flow of information in normal reading.

\section{EXPERIMENT 2}

In order to investigate further whether the reduction observed in Stroop interference is due to disruption of phonemic processing of the written word, a second experiment was carried out to compare performance in a Stroop task while subjects were concurrently engaged in each of several different tasks. To insure that the previously obtained results were not peculiar to the card-sorting paradigm employed, a two-choice reaction time task with tachistoscopically presented stimuli was used. Subjects had to make judgments as quickly as possible about the ink color of the same three types of stimuli as in Experiment 1. Simultaneously, they were required to remain silent, continuously articulate an irrelevant syllable, perform a graphemic judgment task (concerning the shape of letters), or perform a phonemic judgment task

Table 2

Mean Numbers of Sorts on Which One or More Errors Were Made (Maximum of Two)

\begin{tabular}{lccc}
\hline $\begin{array}{c}\text { Type of } \\
\text { Instruction }\end{array}$ & $\mathbf{X X X X X} \begin{array}{c}\text { Con- } \\
\text { gruent } \\
\text { Words }\end{array}$ & $\begin{array}{c}\text { Incon- } \\
\text { gruent } \\
\text { Words }\end{array}$ \\
\hline Silent & .10 & 0 & .40 \\
Continuous Articulation & .10 & .05 & .10 \\
\hline
\end{tabular}

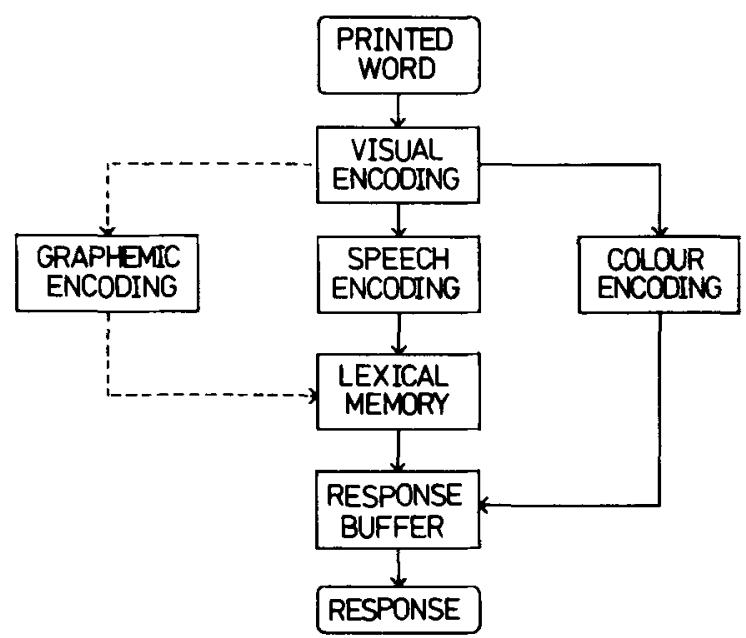

Figure 1. A possible model of reading and the Stroop task.

(concerning the sound of letters). The latter two conditions were added to those of the previous experiment so as to allow additional assessment of the contribution of the graphemic and phonemic routes shown in Figure 1.

The measure of the magnitude of the Stroop effect used here was the difference between the mean reaction times to the incongruent words and the colored Xs. This measure was chosen from the 11 previously proposed derived measures of the Stroop effect reviewed by Jensen $(1965 \mathrm{~b}$ ) because it is a direct measure of the amount of interference between the word and ink color and has been shown to be reasonably stable under test-retest conditions.

\section{Individual Differences}

The Stroop color-word test has been shown previously to yield significant correlations with a range of other, often more complex, psychological measures (Jensen \& Rohwer, 1966). Two factors whose relation to Stroop performance is of particular theoretical interest are those of reading speed and personality type.

According to the race theory (Morton \& Chambers, 1973), it would be expected that fast readers should show a larger Stroop effect than slow readers, because the irrelevant information from the name of the word should become available faster and thereby cause more interference than for slow readers. This prediction will not hold, however, if the faster readers also have a correspondingly faster reaction time to ink color; some evidence for this is provided by a study reported by Thurstone (1944). Thurstone found that fast readers responded significantly faster to ink color, and there was no significant difference in Stroop impairment in the two groups. In the present study, subjects were assessed on the basis of their speed of reading of random word passages rather than normal prose passages, since the former resemble the isolated words of Stroop stimuli more closely. 
Second, a large body of research has examined the relationship between personality factors and performance on the Stroop test. Jensen (1965a) found only very low correlations (less than .15 ) between a Stroop measure and the extraversion (E) and neuroticism (N) scales of the Maudsley Personality Inventory (MPI). However, recently a new version of this questionnaire, the Eysenck Personality Questionnaire (Eysenck \& Eysenck, 1975) has been devised, which incorporates what may be a particularly relevant new scale, psychoticism (P). Subjects who score highly on the P scale might be expected to show a larger Stroop effect because nonparanoid schizophrenics (high P scorers) appear to demonstrate a widening of selective attention that precludes them from inhibiting irrelevant stimuli (Dykes \& McGhie, 1969; Payne, 1961; Shakow, 1963; Silverman, 1964; Weckowicz, 1957).

Thus the present experiment included the testing of subjects' reading speeds and the administration of the Eysenck Personality Questionnaire in addition to the assessment of Stroop performance.

\section{Method}

Subjects. Twenty new subjects from the Oxford Long-Term Subject Panel participated in this experiment. There were equal numbers of males and females and their ages were between 18 and 30 years.

Materials and Apparatus. Blank white cards measuring $10.2 \times 15.2 \mathrm{~cm}$ and two different colored inks (green and brown) were used. The symbols were placed in the center of the card. The letters were $.8 \mathrm{~cm}$ tall and altogether $3.2 \mathrm{~cm}$ in width and were viewed at a fixed distance of $40.6 \mathrm{~cm}$ in a twofield tachistoscope with a viewing area of $7.6 \times 12.7 \mathrm{~cm}$. Three different types of cards were prepared. Control cards had XXXXX written on them in either green or brown ink. Congruent cards had either the word "GREEN" written in green ink or the word "BROWN" written in brown ink. Incongruent cards had either the word "BROWN" written in green ink or the word "GREEN" written in brown ink. A set of 24 such cards was prepared for the practice trials and 144 for the experimental trials. The subsidiary task to be carried out by each subject in each trial was specified on the back of the relevant card.

Seventy-two words each eight letters in length were selected with frequency of occurrence between four and seven in the Kucera and Francis (1967) corpus. Half of these words were used in a graphemic task in which subjects had to count the number of curved letters if the words were printed in capital letters (e.g., the correct response for the word "SPLINTER" was "three"). The other half were used in a phonemic task in which subjects had to count the number of letters rhyming with "see" in normal alphabetic recitation (e.g., the correct response for the word "CONVINCE" was "four"). The correct response in each case varied between one and five, the distributions being the same for the phonemic and the graphemic tasks.

For assessing speed of reading, 200-word passages constructed by Martin (1977) were used. Each passage consisted of a section from a novel by London, Poe, or Faulkner with the order of the words in each sentence randomized using random numbers.

Personality was assessed by means of the Eysenck Personality Questionnaire (Eysenck \& Eysenck, 1975). This questionnaire incorporates a psychoticism (P) scale as well as those for extraversion (E), neuroticism $(\mathrm{N})$, and dissimulation $(\mathrm{L})$.
Procedure. Subjects were tested individually in a quiet testing room. Each subject first served in the Stroop experiment. All subjects received the practice trials in the same order. The experimental trials were divided into nine blocks of 16 cards each. Within a block, cards were all of the same type (e.g., all cards were of the congruent-word type). The order in which the conditions were carried out was counterbalanced across subjects. The cards within a block were shuffled for each subject, which meant that the order in which the subsidiary tasks were carried out was randomized within a block. For half the subjects, the left button corresponded to green and the right button to brown, while for the other half, the relationship was reversed.

Typed instructions explaining the task were given to each subject at the start of the experiment. Subjects were required always to respond, as fast as was possible without making errors, to the color of the ink on the card, irrespective of what was written on the card. Concurrently with the reaction time task, subjects were required to carry out one of four subsidiary conditions. These were continuous articulation (saying the syllable "bla" aloud repeatedly as fast as possible), silent viewing (with no additional task), graphemic judgment (of the number of curved letters in a word), and phonemic judgment (of the number of letters rhyming with "see" in a word). Subjects looked at the black central fixation spot on a white background in the tachistoscope. The experimenter put the stimulus card into the tachistoscope and then instructed the subject to commence a particular subsidiary task, informing him of the relevant word if it was a judgment task. The experimenter then initiated the presentation of the stimulus card, which lasted $1 \mathrm{sec}$. The subject decided whether the ink was green or brown and pressed the appropriate button as fast as possible. The time elapsed between the onset of the stimulus and the response was shown on an electronic timer and noted by the experimenter. In the graphemic and phonemic conditions, the subject then gave his estimate of the number of letters of the appropriate type. Any trials in which the subject made an error on the Stroop task were rerun at the end of the session. The mean reaction time of the 12 correct trials for each condition was used in the analy sis of the data.

After completing the Stroop part of the experiment, subjects were given further instructions explaining that they were to read aloud from passages of randomized words as fast as possible, and without regard to intonation, but to avoid missing any words or adding in any words. The time taken to read each passage was measured using a stopwatch.

Finally, the Eysenck Personality Questionnaire was administered, with subjects allowed as long as they required to answer the questions.

\section{Results and Discussion}

Mean reaction times averaged over subjects are shown in Table 3 for the silent and continuous articulation conditions, which constituted a replication of Experiment 1 using a different experimental method. A four-way analysis of variance (card type by articulation instruction by subjects by sex) on mean reaction times for each subject was carried

Table 3

Mean Reaction Time (in Milliseconds) in Experiment 2 for Articulation and Nonarticulation Instructions

\begin{tabular}{lcccc}
\hline $\begin{array}{c}\text { Type of } \\
\text { Instruction }\end{array}$ & XXXXX & $\begin{array}{c}\text { Con- } \\
\text { gruent } \\
\text { Words }\end{array}$ & $\begin{array}{c}\text { Incon- } \\
\text { gruent } \\
\text { Words }\end{array}$ & $\begin{array}{c}\text { Size of } \\
\text { Stroop } \\
\text { Effect }\end{array}$ \\
\hline $\begin{array}{l}\text { Silent } \\
\begin{array}{l}\text { Continuous } \\
\text { Articulation }\end{array}\end{array}$ & 414.08 & 411.49 & 554.62 & 140.54 \\
\hline
\end{tabular}


out. The main effect of card type was significant $[F(2,36)=37.70, p<.001]$. The interaction between card type and articulation instruction was also significant $[F(2,36)=4.80, p<.025]$. None of the other main effects or interactions reached significance. The mean reaction times were examined further using the Newman-Keuls technique.

Mean reaction times were significantly slower to incongruent cards than to colored $\mathrm{Xs}$ or congruent cards in both the silent and articulation conditions $(p<.01)$, confirming the occurrence of the visual Stroop effect in a task where no verbal response had to be made. The most important result was that the addition of continuous articulation significantly speeded up responses only for the incongruent cards $(p<.01)$, thereby confirming the results of Experiment 1 . The error rate was low throughout (mean $=4.38 \%)$ and did not differ significantly among the different conditions.

Mean reaction times averaged over subjects are shown in Table 4 for the graphemic and phonemic conditions. A four-way analysis of variance (card type by secondary task by subjects by sex) on mean reaction times for each subject was carried out. The main effect of card type was significant $[F(2,36)=24.19, p<.001]$. The interaction between card type and secondary task (graphemic or phonemic) was also significant $[F(2,36)=4.10, p<.025]$. None of the other main effects or interactions reached significance. The mean reaction times were examined further using the Newman-Keuls technique.

Mean reaction times were significantly slower to incongruent cards than to colored $\mathrm{Xs}$ or congruent words with either concurrent graphemic or phonemic tasks $(\mathrm{p}<.01)$, confirming the occurrence of the Stroop effect. The most important result was that responses to incongruent cards were significantly faster when concurrently carrying out a phonemic task than when carrying out a graphemic task $(\mathrm{p}<.01)$, but there were no significant differences for reaction times to colored Xs and congruent words between phonemic and graphemic tasks. The error rate was low (mean $=2.9 \%$ ) and did not differ significantly between the different conditions.

Accuracy of performance on the graphemic and phonemic tasks was assessed by considering the difference between the judged and correct number of letters in each case. These differences were subjected to a four-way analysis of variance (type of task by type

Table 4

Mean Reaction Time (in Milliseconds in Experiment 2 for Graphemic and Phonemic Tasks

\begin{tabular}{lcccc}
$\begin{array}{c}\text { Type of } \\
\text { Instruction }\end{array}$ & XXXXX & $\begin{array}{c}\text { Con- } \\
\text { gruent } \\
\text { Words }\end{array}$ & $\begin{array}{c}\text { Incon- } \\
\text { gruent } \\
\text { Words }\end{array}$ & $\begin{array}{r}\text { Size of } \\
\text { Stroop } \\
\text { Effect }\end{array}$ \\
\hline Graphemic & 601.05 & 553.42 & 729.89 & 128.84 \\
Phonemic & 594.16 & 572.39 & 666.03 & 71.87 \\
\hline
\end{tabular}

of card by subjects by sex). There were no significant main effects or interactions. However, there was a trend toward the interaction of Type of Task by Sex $[F(1,18)=3.01, p<.10]$, previously reported by Coltheart, Hull, and Slater (1975). The total discrepancy between the correct and the judged numbers of letters for males was 131 on the graphemic task and 171 on the phonemic task, whereas the females' figures were 116 and 106 , respectively.

Individual differences. Performance on the silent conditions of the Stroop test was examined in relation to reading speed and the Eysenck Personality Questionnaire.

The subjects were first divided into two equal groups on the basis of the mean time taken to read the three passages of random words. The 10 faster subjects took a mean time of $68.29 \mathrm{sec}$ to read the 200 words and the 10 slower subjects $76.71 \mathrm{sec}$. Mean reaction times on the Stroop task are shown in Table 5 for fast and slow readers. A three-way analysis of variance (card type by speed of reader by subjects) revealed a significant interaction between type of card and speed of reader $[F(2,36)=4.01, p<.05]$. There was a significant main effect of card type $[F(2,36)=42.09, p<.001]$, but no other significant main effects or interactions. The mean reaction times were examined further using the Newman-Keuls technique.

Fast readers took significantly longer to respond to incongruent cards than did slow readers $(p<.01)$, but there was no significant difference between readers for Xs or congruent words. For both fast and slow readers, incongruent words were responded to slower $(p<.01)$ than Xs or congruent words, which did not differ significantly.

The subjects were then divided into two equal groups on the basis of scores on each of the four EPQ personality scales. The high-psychoticism (P) group had a mean score of 9.7 and the low-P group a mean score of 3.8 , while for extraversion (E), neuroticism $(\mathrm{N})$, and dissimulation (L), the figures were 18.7 and $8.2,14.6$ and 7.3 , and 7.6 and 1.5 , respectively. Four separate three-way analyses of variance (personality score by card type by subjects) were performed on the reaction time data from the Stroop task. There were no significant main effects or interactions for any of the personality dimensions. There was, however, a nonsignificant trend in the predicted direction: high $\mathrm{P}$ scorers showed a larger mean Stroop effect $(152.93 \mathrm{msec})$ than did low $\mathbf{P}$ scorers $(128.39 \mathrm{msec})$.

Table 5

Mean Reaction Time (in Milliseconds) for Fast and Slow Readers in the Silent Condition in Experiment 2

\begin{tabular}{lcccr}
\hline $\begin{array}{c}\text { Speed of } \\
\text { Reader }\end{array}$ & XXXXX & $\begin{array}{c}\text { Con- } \\
\text { gruent } \\
\text { Words }\end{array}$ & $\begin{array}{l}\text { Incon- } \\
\text { gruent } \\
\text { Words }\end{array}$ & $\begin{array}{r}\text { Size of } \\
\text { Stroop } \\
\text { Effect }\end{array}$ \\
\hline Fast & 422.06 & 414.26 & 603.57 & 181.51 \\
Slow & 406.10 & 408.73 & 505.67 & 99.57 \\
\hline
\end{tabular}




\section{GENERAL DISCUSSION}

Irrelevant articulation led to a decrease in the extent of the Stroop effect in both experiments, implying that skilled readers usually translate the visual representation of a word into a speech representation in order to access the meaning of the word, although readers may also use a slower graphemic route to lexical memory (as shown in Figure 1). This hypothesis was further supported by the greater reduction in the Stroop effect when subjects were concurrently engaged in a phonemic rather than a graphemic task.

An alternative explanation for the reduction in the Stroop effect observed when subjects are continuously articulating is that it is due to increased arousal from articulating. Easterbrook (1959) proposed that an increase in arousal causes a restriction of the range of cues that the organism uses in the guidance of its actions, producing a beneficial tendency to focus on a relevant cue. However, the selection of relevant cues must also involve a discrimination between these cues and others. A state of high arousal tends to impair such discriminations, consequently counteracting the increased tendency to focus on the relevant cues by a reduced ability to do so (Kahneman, 1973). Furthermore, conflicting results are obtained on the Stroop test when arousal is manipulated by the use of noise (Broadbent, in press) or drugs. O'Malley and Poplawsky (1971) reported an improvement in performance for incongruent stimuli in $85-\mathrm{dB}$ noise, but there was a similar improvement in color naming. Hartley and Adams (1974) found increased interference in $100-\mathrm{dB}$ noise in their first experiment, but in a second experiment, where exposure duration and practice were assessed independently, the brief exposure to $95-\mathrm{dB}$ noise was beneficial and decreased interference, and the long exposure increased interference, suggesting a cumulative adverse effect of noise. Callaway (1959) found that subjects given a depressant drug (amobarbital) showed a decrease in interference on the Stroop test compared with subjects given a placebo. However, Quarton and Talland (1962) repeated Callaway's (1959) experiment with slight modifications, using pentobarbital and methamphetamine, and found no significant effects on Stroop interference.

An arousal explanation of the reduction in the Stroop effect with continuous articulation thus has only tenuous experimental support. Conversely, when a decrease in Stroop interference is observed in noise, it may be due to inhibition of phonemic processing rather than to a change in arousal. Furthermore, it seems unlikely that different arousal levels are induced in subjects by the concurrent graphemic and phonemic tasks, although these also were shown to have differential effects upon Stroop performance.

Support was found here for the race model of the Stroop effect (Cohen \& Martin, 1975; Morton \&
Chambers, 1973), in which interference is attributed to the irrelevant attribute of the stimulus becoming available to the response system before the relevant one. As predicted, fast readers, who were not also faster in reaction time to color alone, showed larger Stroop interference than slow readers.

The size of the Stroop effect was not affected significantly by personality factors, which is consistent with the findings of Jensen (1965a), although there was a nonsignificant trend for high $\mathrm{P}$ scorers to show a larger Stroop effect than low $\mathrm{P}$ scorers. It may be relevant that Jorgenson (1977) reported a curvilinear relationship between Stroop interference and anxiety level (measured by the Spielberger, 1970, State-Trait Anxiety Inventory). Low- and high-anxiety females showed a larger Stroop effect than did medium-anxiety females. Thus an underlying curvilinear relationship between Stroop performance and personality variables may account for the lack of significant results obtained by studies using linear regression or the division of subjects into two groups only.

In conclusion, the results of the two experiments provide support for the dual-encoding hypothesis of reading (e.g., Baron, 1973; LaBerge, 1972), which states that reading involves converting a visual representation into a speech code, and that both visual and speech codes provide access to lexical memory.

\section{REFERENCES}

Baron, J. Phonemic stage not necessary for reading. Quarterly Journal of Experimental Psychology, 1973, 25, 241-246.

Bower, T. G. R. Reading by eye. In H. Levin \& J. P. Williams (Eds.), Basic studies on reading. New York: Basic Books, 1970.

BRADShaw, J. L. Three interrelated problems in reading: A review. Memory \& Cognition, 1975, 3, 123-134.

Broadbent, D. E. Human performance in noise. In C. $M$. Harris (Ed.), Handbook of noise control. New York: McGraw-Hill, in press.

Callaway, E. The influence of amobarbital (amylobarbitone) and methamphetamine on the focus of attention. Journal of Mental Science, 1959, 105, 382-392.

Cohen. G.. \& Martin, M. Hemisphere differences in an auditory Stroop test. Perception \& Psychophysics, 1975, 17, 79.83.

Coltheart, M., Hull, E., \& Slater, D. Sex differences in imagery and reading. Nature, 1975, 263, 438-440.

Conrad, R. Acoustic confusion in immediate memory. British Journal of Psychology, 1964, 55, 75-84.

Dýes, M., \& MCGHIE, A. A comparative study of attentional strategies of schizophrenic and highly creative normal subjects. British Journal of Psychiatry, 1976, 128, 50-56.

EASTERBRoOK, J. A. The effect of emotion on cue utilization and the organization of behavior. Psychological Review, 1959, 66, 183-201.

Edfelt, A. W. Silent speech and silent reading. Chicago: University of Chicago Press, 1960.

Eysenck, H. J., \& EysENCK, S. B. G. Manual of the Eysenck Personality Questionnaire. London: Hodder \& Stoughton, 1975.

Flowers, J. H., \& Dutch, S. The use of visual and name codes in scanning and classifying colors. Memory \& Cognition, 1976, 4. 384-390. 
Flowers, J. H., \& Stoup, C. M. Selective attention between words, shapes, and colors in speeded classification and vocalization tasks. Memory \& Cognition, 1977, 5, 299-307.

Hartley, L. R., \& Adams, R. G. Effect of noise on the Stroop test. Journal of Experimental Psychology, 1974, 102, 62-66.

HUEY, E. B. The psychology and pedagogy of reading. New York: Macmillan, 1908.

JENSEN, A. R. Individual differences in learning: Interference factor. Final Report, Cooperative Research Project No. 1867, U.S. Office of Education, 1965. (a)

Jensen, A. R. Scoring of the Stroop test. Acta Psychologica, $1965,24,398-408$. (b)

JENSEN, A. R., \& RoHwER, W. D., JR. The Stroop color-word test: A review. Acta Psychologica, 1966, 25, 36-93.

JoRgenson, C. B. Visual set and anxiety in the Stroop phenomenon. Perceptual and Motor Skills, 1977, 44, 659-667.

Kahneman, D. Attention and effort. Englewood Cliffs, N.J: Prentice-Hall, 1973.

KEELE, S. W. Attention demands of memory retrieval. Journal of Experimental Psychology, 1972, 93, 245-248.

KLEIman, G. M. Speech recoding in reading. Journal of Verbal Learning and Verbal Behavior, 1975, 14, 323-339.

Kolers, P. A. Three stages in reading. In H. Levin \& J. P. Williams (Eds.), Basic studies of reading. New York: Basic Books, 1970.

Kú̌ERA, H., \& Francis, W. N. Computational analysis of present-day American English. Providence, R.I: Brown University Press, 1967.

LABERGE, D. Beyond auditory coding: A discussion of Conrad's paper. In J. F. Kavanagh \& I. G. Mattingly (Eds.), Language by ear and by eye: The relationship between speech and reading. Cambridge, Mass: MIT Press, 1972.

LEVY, B. A. Role of articulation in auditory and visual shortterm memory. Journal of Verbal Learning and Verbal Behavior, 1971, 10, 123-132.

LEVY, B. A. Vocalization and suppression effects in sentence memory. Journal of Verbal Learning and Verbal Behavior, $1975,14,304-316$.

Martin, M. Reading while listening: A linear model of selective attention. Joumal of Verbal Learning and Verbal Behavior, 1977, 16, 453-463.

McGhie, A. Pathology of attention. Harmondsworth: Penguin Books, 1969.

Meyer, D. E., Schvaneveldt, R. W., \& Ruddy, M. G. Functions of graphemic and phonemic codes in visual word recognition. Memory \& Cognition, 1974, 2, 309-321.
Morton, J., \& Chambers, S. M. Selective attention to words and colors. Quarterly Journal of Experimental Psychology, 1973, 25, 387-397.

MurRay, D. J. Articulation and acoustic confusability in short-term memory. Journal of Experimental Psychology, 1968, 78, 679-684.

O'Malley, J. J., \& Poplawsky, A. Noise-induced arousal and breadth of attention. Perceptual and Motor Skills, $1971,33,887-890$.

PAyne, R. W. Cognitive abnormalities. In H. J. Eysenck (Ed.), Handbook of abnormal psychology. New York: Basic Books, 1961.

Peterson, L. R., \& Johnson, S. F. Some effects of minimizing articulation on short-term retention. Journal of Verbal Learning and Verbal Behavior, 1971, 10, 346-354.

Quarton, G. C., \& Talland, G. A. The effects of methamphetamine and pentobarbital on two measures of attention. Psychopharmacologia, 1962, 3, 66-71.

Rubenstein, H.. Lewis, S. S., \& Rubenstein, M. A. Evidence for phonemic recoding in visual word recognition. Journal of Verbal Learning and Verbal Behavior, 1971, 10, 645-657.

Schmit, V., \& Davis, R. The role of hemispheric specialization in the analysis of Stroop stimuli. Acta Psychologica, 1974, 38, 149-158.

SHAKow, D. Psychological deficit in schizophrenia. Behavioral Science, 1963, 8, 275-305.

Silverman, J. Scanning control and cognitive filtering. Journal of Consulting Psychology, 1964, 28, 385-394.

SMITH, F. Understanding reading: $A$ psycholinguistic analysis of reading and learning to read. New York: Holt, Rinehart, \& Winston, 1971.

Spielberger, C. D., Gorsuch, R. L., \& Lushene, R. E. Manual for the State-Trait Anxiety Inventory, Palo Alto: Consulting Psychologists Press, 1970.

STROop, J. R. Studies of interference in serial verbal reactions. Journal of Experimental Psychology, 1935, 18, 643-661.

Thurstone, L. L. A factorial study of perception. Chicago: University of Chicago Press, 1944.

WeCkowicz, T. E. Size constancy in schizophrenic patients. Journal of Mental Science, 1957, 103, 432-486.

(Received for publication August 30, 1977; accepted November 7,1977 .) 